\title{
Meio ambiente e desenvolvimento: análise do caso de parcelamento irregular do solo na perspectiva dos direitos humanos
}

\author{
Environment and development: analysis of split \\ irregular urban land in a human rights perspective
}

\section{Ingrid Giachini Althaus ${ }^{[a]}$, Tiago Gagliano Pinto Alberto ${ }^{[b]}$}

\begin{abstract}
[a] Advogada e professora de ensino superior, Mestranda em Direito Econômico e Socioambiental da Pontifícia Universidade Católica do Paraná (PUCPR), Curitiba, PR - Brasil, e-mail: ingridalthaus@uol.com.br

[b] Juiz de Direito e professor de ensino superior, Mestrando em Direito Econômico e Socioambiental da Pontifícia Universidade Católica do Paraná (PUCPR), Curitiba, PR - Brasil, e-mail: tiagogagliano@hotmail.com
\end{abstract}

\section{Resumo}

Como resultado do advento de novos direitos, entre os quais os relacionados à perspectiva do desenvolvimento sustentável alusivo aos direitos humanos socioambientais, a sociedade passa por momento de adaptação em seara pública e privada. Nesse contexto, o parcelamento do solo urbano, se empreendido de maneira a atender as diretrizes legais e sociais, revela-se como meio apto a viabilizar o desenvolvimento pleno da sociedade e não o mero crescimento econômico. Ao revés, se realizado de maneira paralela ao ordenamento jurídico e desconsiderando parâmetros principiológicos hodiernos, ter-se-á não 
uma forma de evolução no trato dos direitos humanos relativos ao ecodesenvolvimento, senão distribuição do solo que não atenda aos anseios sociais. O presente trabalho visa empreender análise acerca destes novos direitos e sua necessária correlação com o desenvolvimento do país por meio do parcelamento do solo urbano.

Palavras-chave: Desenvolvimento. Meio ambiente. Parcelamento do solo urbano.

\section{Abstract}

As a result of the advent of new rights, including those related to the sustainable development approach to human rights, society undergoes adaptation in public and private approach. In this context, urban land subdivision, if undertaken in order to meet the legal guidelines and social, shows itself as a suitable means to enable the full development of society and not just economic growth. In reverse, if performed in parallel to the legal parameters and disregarding principle, will have not a form of evolution in human rights deal for the eco-development, but the distribution of soil that does not meet social expectations. This paper aims to undertake analysis on these new rights and their necessary correlation with the development of the country through the parceling of urban land.

Keywords: Development. Environment. Urban land subdivision.

\section{Introdução}

O desafio do século XX foi instituir novas formas de direito, em razão dos crescentes anseios sociais e ambientais, advindos do capitalismo, ou seja, de uma nova realidade.

O capitalismo, envolto por sua expansão, crises, recessões e transformações, marcou a história, seja no campo da economia, no social, da política e da ideologia (MOREIRA, 1978, p. 11).

Assim, após a Segunda Guerra Mundial foram intensas as discussões sobre os intitulados "novos direitos", dentre eles os direitos humanos 
internacionais, que compreendem os direitos ao meio ambiente ecologicamente equilibrado e ao desenvolvimento.

O presente artigo tem o objetivo de tratar do problema do desenvolvimento sustentável dentro da perspectiva dos direitos humanos socioambientais.

Para elucidar essa questão, propõe-se, ainda, o estudo do parcelamento irregular do solo urbano como obstáculo ao desenvolvimento nacional, além de meio de infração aos direitos humanos socioambientais.

Para tanto, abordar-se-á o direito ao desenvolvimento e, especificamente, a relação entre esse direito o meio ambiente e os direitos humanos. E, por fim, o estudo do caso de parcelamento do solo urbano, de forma irregular, a fim de demonstrar a necessidade de políticas publicas adequadas nesse campo para mudar o quadro de violação aos direitos humanos que até então presenciamos no país.

\section{O direito ao desenvolvimento}

Segundo Fábio Nusdeo (2009, p. 341-395), uma organização político-econômica considera-se estaticamente eficiente no momento em que

há a "ocupação da capacidade produtiva do sistema econômico e dos seus recursos humanos de forma plena". Por este motivo, a tendência atual é preconizar a idéia de eficiência dinâmica, que para ser realizada exige uma "permanente e auto-sustentada evolução em toda a estrutura, não apenas econômica, mas social e cultural”. Foi em busca deste dinamismo econômico-social que os Estados protagonistas do pós-guerra iniciaram um novo "processo desenvolvimentista.

E, ainda, nessa linha de raciocínio, explica que (NUSDEO, 2009, p. 243)

em uma conceituação vinda da área econômica e já bastante consolidada, "crescimento econômico" é o aumento do produto nacional em 
termos globais ou per capita num período determinado (na melhor das hipóteses, pelo aumento de eficiência no sistema produtivo). O "desenvolvimento econômico" é o aumento quantitativo do produto nacional acompanhado por modificações qualitativas referentes ao bem-estar social. Ou seja, o crescimento do produto nacional, somado ao crescimento do consumo, da renda per capita e das exportações deve ser justaposto aos índices relativos à diminuição dos níveis de pobreza e de desemprego, além da elevação das condições de saúde, nutrição, educação, moradia e segurança, para que exista desenvolvimento. Portanto, é possível crescer sem se desenvolver, mas jamais se desenvolver sem crescer.

O desenvolvimento, lembra Emerson Gabardo, "em geral, é definido pelos autores como um processo autossustentado. Um processo que faz, portanto, as condições de vida se elevarem continuamente ao longo de um dado período. Por consequência, a expressão "desenvolvimento auto-sustentado", na realidade, é tautológica. Se o desenvolvimento não for autossustentado, é apenas crescimento, ainda que venha acompanhado de melhorias no tocante ao bem-estar social" (NUSDEO, 2009, p. 243).

Porém, utilizando-se das palavras de Luiz Carlos Pereira Bresser, "para que ocorra realmente um processo de desenvolvimento a melhoria do padrão de vida da população deverá tender a ser automática, autônoma e necessária” (NUSDEO, 2009, p. 243).

Não obstante, os

fins e os meios do desenvolvimento requerem análise e exame minuciosos para uma compreensão mais plena do processo de desenvolvimento; é sem dúvida inadequado adotar como nosso objetivo básico apenas a maximização da renda ou da riqueza, que é, como observou Aristóteles, "meramente útil e em proveito de alguma outra coisa." Pela mesma razão, o crescimento econômico não pode sensatamente ser considerado um fim em si mesmo. O desenvolvimento tem de estar relacionado sobretudo com melhora da vida que levamos e das liberdades que se desfrutamos. Expandir as liberdades que temos razão para valorizar não só torna nossa vida mais rica e mais desimpedida, mas também permite que sejamos seres sociais mais completos, pondo em 
prática nossas volições, interagindo com o mundo em que vivemos e influenciando esse mundo (SEN, 2008, p. 28-29).

Contrariando as visões que o relacionam somente aos processos de aumento de renda e de riqueza, bem como ao avanço tecnológico e social, como ensina Amartya Sen (2008, p. 17), o desenvolvimento, também, deve "ser visto como um processo de expansão das liberdades reais que as pessoas desfrutam."

O mesmo autor, enfatiza, ainda, que as liberdades estão atreladas ao desenvolvimento econômico e social, bem como aos direitos políticos e civis. Assim, defende que

às vezes a ausência de liberdades substantivas relacionam-se diretamente com a pobreza econômica, que rouba das pessoas a liberdade de saciar a fome, de obter uma nutrição satisfatória ou doenças tratáveis, a oportunidade de vestir-se ou morar de modo apropriado, de ter acesso à água tratada ou ao saneamento básico. Em outros casos, a privação de liberdades vincula-se estreitamente à carência de serviços públicos e assistência social, como, por exemplo, a ausência de programas epidemiológicos, de um tratamento bem planejado de assistência medica e educação ou de instituições eficazes para a manutenção da paz e da ordem locais. Em outros casos a violação da liberdade resulta diretamente de uma negação de liberdades políticas e civis por regimes autoritários e de restrições impostas à liberdade de participar da vida social, política e econômica da comunidade (SEN, 2008, p. 18).

Entretanto, na década de 60, os limites do desenvolvimento foram uma preocupação constante, diante da crise do meio ambiente que permeava o mundo; ou seja, iniciava-se aqui um forte debate, também, sobre os riscos da degradação ambiental diante do desenvolvimento. Pelo que, como bem leciona Ignacy Sachs (2007, p. 11), a

difusão do conceito seminal de ecodesenvolvimento, a partir de 1972, acompanhou as primeiras iniciativas voltadas para a promoção de um outro tipo de crescimento econômico e de uma repartição qualitativamente diferente dos seus frutos. Por implicação, as concepções 
dominantes acerca das finalidades básicas, dos mecanismos de planejamento e dos critérios de avaliação de políticas, programas e projetos de modernização passaram a ser focalizadas de uma perspectiva radicalmente diferente.

E, como complementa o professor Dr. Marés Filho (1999, p. 315),

no confronto com a economia planificada e o socialismo, o Estado evoluiu e o seu Direito também, passando a intervir profundamente na sociedade, entrando no controle da ordem econômica, interferindo na distribuição de riquezas, de benefícios sociais, de saber. $\mathrm{O}$ direito construiu novos conceitos, institutos e razões, sem perder, porém, a ligação com a cultura contratual e constitucional da aquisição de direitos e da propriedade como a suprema liberdade. O Estado do BemEstar Social, ou Estado-Providência, reviu sua função. Os novos conceitos surgidos redefiniram o Direito Público que passou a organizar não só a própria estrutura do Estado como pessoa de natureza especial, que exerce seus direitos de forma especial, mas também cria formas do Estado intervir nos direitos individuais, relativizando-os, reordenando-os, independentemente e até mesmo contra a vontade dos titulares. O espaço público avançou sobre o espaço privado, tornando ordem pública a que antes era privada. Assim, por exemplo, o direito civil era quem definia o que era domínio público, enquanto no Estado do Bem-Estar Social é o direito público que define como se exercita a propriedade para que ela cumpra uma função social.

Assim, após a Conferência sobre Meio Ambiente de Estocolmo, promovida pela ONU, passa-se a considerar o "atendimento das necessidades humanas fundamentais (materiais e intangíveis), promoção da autoconfiança (self-reliance) das populações envolvidas e cultivo da prudência ecológica" (SEN, 2008, p. 12), ou seja, firma-se um novo conceito de desenvolvimento, dando passagem ao referido ecodesenvolvimento.

Nesse passo, a Assembleia Geral da Organização das Nações Unidas, por meio da Resolução 36/133, de 1981, firmou que o direito ao desenvolvimento é um direito humano inalienável. 
Dessa forma, em 1986, proclamou-se o direito ao desenvolvimento, na Declaração sobre o Direito ao Desenvolvimento das Nações Unidas. Isso porque

na realidade deve-se entendê-lo precipuamente como um legítimo "direito fundamental", seja no plano interno, seja no internacional. No plano interno, alguns autores como Gustavo Henrique Justino de OLIVEIRA apontam como plenamente admissível enquadrar o desenvolvimento como um direito fundamental decorrente, protegido pelo parágrafo $2^{\circ}$ do artigo $5^{\circ}$ da Constituição, que estabelece: "os direitos e garantias expressos nesta Constituição não excluem outros decorrentes do regime e dos princípios por ela adotados, ou dos tratados internacionais em que a República Federativa do Brasil seja parte”. O autor ainda esclarece que a Resolução no 41/128 da Assembléia Geral das Nações Unidas, de 04 de dezembro de 1986, que consagrou a Declaração sobre o Direito ao Desenvolvimento da ONU, estabelece que: "o desenvolvimento é um processo econômico, social, cultural e político abrangente, que visa ao constante incremento do bem-estar de toda a população e de todos os indivíduos com base em sua participação ativa, livre e significativa no desenvolvimento e na distribuição justa dos benefícios daí resultantes (GABARDO, 2009, p. 246).

O direito ao desenvolvimento deve ser compreendido, essencialmente, "como um direito humano inalienável, em virtude do qual toda pessoa humana e todos os povos estão capacitados a desfrutar do desenvolvimento econômico, social, cultural e político" (TRINDADE, 1993, p. 174).

Nesse sentido, como escreve Maria Heliodora do Vale Romeiro Collaço (2010), tem-se que,

contudo, a Resolução 41/128 da Assembléia Geral da ONU, realizada em dezembro de 1986 dispôs sobre o direito ao desenvolvimento "como processo econômico, social, cultural e político abrangente, que visa ao constante incremento do bem-estar de toda a população e de todos os indivíduos com base em sua participação ativa, livre e significativa no desenvolvimento e na distribuição justa dos benefícios daí resultantes". Todavia, a possibilidade de exercício pleno dos direitos 
civis e políticos anteriormente consagrados na ordem internacional é precária e, até mesmo, impossível, apartada do gozo dos direitos econômicos e sociais. Trata-se, portanto, do reconhecimento da necessidade de promoção das potencialidades do homem em prol do aprimoramento de sua personalidade como também da satisfação de suas necessidades. Desta forma, o direito ao desenvolvimento é, concomitantemente, um direito individual, inerente a todo ser humano e, também, um direito de todos os povos. Direito a ser observado e concretizado por todos os Estados nos planos interno e internacional. Daí a obrigação de o Estado formular e implementar políticas públicas aptas a concretizar, na sua plenitude, tal direito. A Declaração Universal dos Direitos Humanos, em seu artigo XXII consagra que "toda pessoa, como membro da sociedade, tem direito à segurança social e à realização, pelo esforço e recursos de cada Estado, dos direitos econômicos, sociais e culturais indispensáveis à sua dignidade e ao livre desenvolvimento de sua personalidade". Entretanto, não basta crescer economicamente. Em muitos casos, isto é tão necessário quanto insuficiente. Imprescindível é aumentar os graus de acesso das pessoas não só à renda, mas à riqueza em si, ao conhecimento, à capacidade e à possibilidade de influir nas decisões públicas. Há que se buscar, efetivamente, o resgate da dignidade de muitos seres humanos.

\section{Mesmo porque o}

subdesenvolvimento (pobreza, falta de moradia, doenças endêmicas, desnutrição, insegurança) leva a uma negação total dos direitos humanos, com fatores imensuráveis. [...] o direito ao desenvolvimento como um direito humano propõe-se a superar possíveis obstáculos para que haja a satisfação de necessidades humanas básicas, como emprego, moradia, lazer, alimentação e educação (FREITAS, 2006, p. 245).

\section{Correlação entre desenvolvimento, meio ambiente e direitos humanos}

$\mathrm{Na}$ Conferência das Nações Unidas sobre Meio Ambiente e Desenvolvimento, no Rio de Janeiro, definiu-se a conhecida "Agenda 21" em resposta à solicitação de um documento que "concretizasse uma política 
global para a preservação e o desenvolvimento sustentável" (CONFERÊNCIA, 1997, p. 9).

Isso porque esse documento surge como "resposta à convocação da Assembléia Geral das Nações Unidas, realizada no dia 22 de dezembro de 1989, feita com o fim de elaborar estratégias que permitissem interromper e reverter os efeitos da degradação ambiental" (CONFERÊNCIA, 1997, p. 9).

Nesse momento, consolidou-se, realmente, a ideia de desenvolvimento sustentável, chamado anteriormente de ecodesenvolvimento, como princípio de direito. Como se depreende das palavras de Luís Paulo Sirvinskas (2009, p. 58), este princípio "procura a proteção do meio ambiente com o desenvolvimento socioeconômico para a melhoria da qualidade de vida do homem. É a utilização racional dos recursos naturais não renováveis".

Anote-se, como diz Sunkel (2001 apud VEIGA, 2008, p. 188), que a

noção de desenvolvimento sustentável, de tanta importância nos últimos anos, procura vincular estreitamente a temática do crescimento econômico com a do meio ambiente. Para compreeender tal vinculação, são necessários alguns conhecimentos fundamentais que permitem relacionar pelo menos três âmbitos: a) o dos comportamentos humanos, econômicos e sociais, que são objeto da teoria econômica e das demais ciências sociais; b) o da evolução da natureza, que é objeto das ciências biológicas, físicas e químicas; c) o da configuração social do território, que é objeto da geografia humana, das ciências regionais e da organização do espaço. É evidente que esses três âmbitos se relacionam, interagem e se sobrepõem, afetando-se e condicionando-se mutuamente. A evolução e a transformação da sociedade e da economia no processo de desenvolvimento alteraram de várias maneiras o mundo natural. E esse relacionamento recíproco se materializa, se articula e se expressa por meio de formas concretas de ordenamento territorial.

A Constituição Federal prevê a proteção ambiental "como um dos princípios da evolução econômica (CF, art. 170, VI), orientando e condicionando o desenvolvimento econômico à proteção ambiental, influindo inclusive 
nas normas legais como vem se dando recentemente, (v.g. Estatuto da $\mathrm{Ci}$ dade), tanto que o desenvolvimento sustentável deve ser visto como um princípio de direito" (FREITAS, 2006, p. 57).

Outrossim, tanto

o direito ao desenvolvimento quanto o direito ambiental devem ser entendidos como direitos humanos internacionais. Já que ambos possuem tal natureza, devem caminhar juntos, com necessária tentativa de harmonização. Assim, foi evoluindo ao longo tempo a figura do desenvolvimento sustentável (FREITAS, 2006, p. 243).

Em contrapartida, ao avanço constitucional, o qual inseriu o desenvolvimento sustentável no rol dos princípios da evolução econômica e, de forma implícita, como critério de solução de antinomias no ordenamento jurídico, tem-se um longo caminho a ser percorrido nesta seara, à vista da nossa realidade.

Utilizando-se das palavras de Leonardo Boff (2009, p. 1), cabe destacar que a

crise atual constitui uma oportunidade única de a humanidade parar, pensar, ver onde se cometeram erros, como evitá-los e que rumos novos devemos conjuntamente construir para sair da crise, preservar a natureza e projetar um horizonte de esperança, promissor para toda a comunidade de vida, incluídas as pessoas humanas.

Como acentua o professor Dr. Carlos Frederico Marés Filho (1999, p. 307), é

visível a crise do Estado e de seu Direito neste final de século. Todos os primados do Direito chamado moderno, seus fundamentos, o direito individual como direito subjetivo, o patrimônio como bem jurídico, a livre manifestação de vontade, estão abalados. Com esse abalo outros dogmas perdem a credibilidade, como a separação de poderes, a neutralidade e o profissionalismo do poder judiciário, a representatividade dos parlamentos, a soberania nacional, a supremacia da Constituição. 
Assim, verificam-se cinco eixos a serem seguidos, quais sejam:

(1) um uso sustentável, responsável e solidário dos limitados recursos e serviços da natureza; (2) o valor de uso dos bens deve ter prioridade sobre seu valor de troca; (3) um controle democrático deve ser construído nas relações sociais, especialmente sobre os mercados e os capitais especulativos; (4) o ethos mínimo mundial deve nascer do intercâmbio multicultural, dando ênfase à ética do cuidado, da compaixão, da cooperação e da responsabilidade universal; (5) a espiritualidade, como expressão da singularidade humana e não como monopólio das religiões, deve ser incentivada como uma espécie de aura benfazeja que acompanha a trajetória humana, pois ancora o ser humano e a história numa dimensão para além do espaço e do tempo, conferindo sentido à nossa curta passagem por este pequeno planeta (BOFF, 2009, p. 3).

Como não poderia deixar de ser, expõe Enrique Leff (2001, p. 346) que

os movimentos sociais emergentes - tanto no campo como nas cidades - estão abrindo um novo espaço político, onde se plasmam as identidades étnicas e as condições ecológicas, para o desenvolvimento sustentável dos povos que habitam o planeta, e da humanidade em seu conjunto.

Isso porque esses "movimentos estão gestando novos direitos ambientais, culturais, coletivos - em resposta a uma problemática ambiental que emerge como uma "crise de civilização", efeito do ponto de saturação e do transbordamento da racionalidade econômica dominante" (LEFF, 2001, p. 346).

Outrossim, essa

inércia globalizadora - que se converte em modelo de vida, pensamento único e medida de todas as coisas - nega e desconhece a natureza, não como uma ordem ontológica e uma organização material da qual emerge a vida, mas em sua constituição, isto é, como uma "ecologia 
produtiva" e como condição de sustentabilidade de toda a ordem econômica e social (LEFF, 2001, p. 346-347).

Ao mesmo tempo, no "campo jurídico, os direitos individuais se tornam marginais e difusos aos direitos coletivos, aqueles compartilhados por uma sociedade como princípios de coesão e solidariedade, e nos quais se fundam as cosmovisões que unem a cultura com a natureza" (LEFF, 2001, p. 347).

\section{Entretanto, os}

novos direitos emergem do grito da natureza e das lutas sociais que reivindicam as formas culturais do ser humano. Esta crise ambiental marca os limites da racionalidade econômica, jurídica e científica que, como fundamento da modernidade, estabelecem o lugar da verdade, os pontos de observação para indagar o mundo e os dispositivos de poder no saber para apropriar-se da natureza (LEFF, 2001, p. 349).

Porém, essa "crise é diferente de outras já havidas e às vezes mal superadas, porque atinge o âmago, os alicerces do sistema jurídico. As correções de rota feitas até agora puderam fazer mudanças no sistema jurídico" (MARÉS FILHO, 1999, p. 307).

Os direitos ambientais são

direitos humanos para com a natureza, incluindo os direitos de propriedade e apropriação da natureza. Os direitos ambientais se definem em relação com as identidades étnicas que se configuraram ao longo da história muito mais em sua relação com seu entorno ecológico do que em relação com uma norma jurídica que corresponde à lógica do mercado ou a uma razão de Estado (MARÉS FILHO, 1999, p. 350).

Mesmo porque, "meio ambiente, entendido em toda a sua plenitude e de um ponto de vista humanista, compreende a natureza e as modificações que nela vem introduzindo o ser humano" (MARÉS FILHO, 2006, p. 15).

Da mesma maneira, 
o meio ambiente é composto pela terra, a água, o ar, a flora e a fauna, as edificações, as obras de arte e os elementos subjetivos e evocativos, como a beleza da paisagem ou a lembrança do passado, inscrições, marcos ou sinais de fatos naturais ou da passagem de seres humanos. Desta forma, para compreender o meio ambiente é tão importante a montanha, como a evocação mística que dela faça o povo (MARÉS FILHO, 2006, p. 15).

Porém, verificam-se elementos que existem "independentes da ação do homem e os chamamos de meio ambiente natural; outros são frutos da sua intervenção e os chamamos de meio ambiente cultural" (MARÉS FILHO, 2006, p. 17).

Assim, embora toda a evolução ocorrida nesse campo,"não há dúvida de que os bens ambientais, naturais e culturais estão em perigo e, com eles, a própria essência das culturas por eles representadas" (MARÉS FILHO, 2006, p. 17).

Contudo, constatam-se sérios problemas a serem vencidos na proteção ambiental, os quais trazem consequências desastrosas para o desenvolvimento do país.

Um deles é o parcelamento irregular do solo urbano, capaz de malferir o direito humano fundamental de desenvolvimento.

Como leciona Carla Rister (2007), nos "países em desenvolvimento", a caótica e intensa urbanização é a manifestação mais visível do processo de desestruturação social. Tanto que as populações ditas marginais seriam a expressão de uma estratificação social que tem suas raízes na modernização.

\section{O caso do parcelamento irregular do solo urbano na nova ordem jurídica}

Vencidas tais considerações, a

preservação do meio ambiente, natural e cultural, não pode ser global, porque isto implicaria impedir qualquer intervenção antrópica 
modificativa do meio ambiente e manteria estático o processo cultural. Preservar toda intervenção humana na natureza ou toda manifestação cultural é um absurdo e uma contradição, porque à guisa de proteger as manifestações passadas, se estaria impedindo que a cultura continuasse a se manifestar (MARÉS FILHO, 2006, p. 15).

Contudo, com o aumento no processo de urbanização no Brasil, pela saída do homem do campo para as cidades, surgiu a necessidade de se regular, de forma uniforme, tal ocupação antrópica do solo para fins urbanos, o que ocorre com a edição da Lei Federal 6.766/79 (BRASIL, 1979).

Essa necessidade se deve, em grande escala, ao nascimento de "novos direitos": os direitos da sociedade, que interferem, alteram e modificam a relação jurídica do sujeito com o objeto de seu direito. São interferências com poder de limitar a propriedade por questões ambientais, sociais, sanitárias, estéticas, históricas, culturais, etc. (RISTER, 2007, p. 316). Deve-se, ainda, à abertura das Constituições a valores e princípios, sendo que a nova ordem jurídica se sustenta no princípio da dignidade da pessoa humana, onde encontra-se seu ponto de partida e chegada (PIOVESAN, 2010, p. 30).

$\mathrm{E}$, quando falamos em parcelamento do solo urbano, recai-se no direito ao meio ambiente ecologicamente equilibrado, ao desenvolvimento, à moradia e à dignidade da pessoa, dentre outros direitos humanos fundamentais.

A Lei Federal 6.766/79 dispôs em seu art. $2^{\circ}$ que o parcelamento do solo urbano pode ser sob a forma de loteamento ou desmembramento.

Em seu $§ 1^{\circ}$ conceitua como "loteamento a subdivisão de gleba em lotes destinados a edificação, com abertura de novas vias de circulação, de logradouros públicos ou prolongamento, modificação ou ampliação das vias existentes".

E, ainda, em $\S 2^{\circ}$ define desmembramento como "a subdivisão de gleba em lotes destinados a edificação, com aproveitamento do sistema viário existente, desde que não implique na abertura de novas vias e logradouros públicos, nem no prolongamento, modificação ou ampliação dos já existentes". 
Porém, verificam-se diversos empecilhos à consagração do direito à vida, à moradia adequada, ao meio ambiente ecologicamente equilibrado e ao desenvolvimento do país ao falarmos nos loteamentos, ante as diversas infrações urbanísticas e ambientais que permeiam este instituto em especial.

São eles a principal forma de expansão urbana. Tanto que o professor José Afonso da Silva os define como "um tipo de parcelamento do solo que se configura no retalhamento de quadras para a formação de unidades edificáveis (lotes) com frente para via oficial de circulação de veículos. O termo refere-se tanto à operação de lotear como ao seu resultado (área loteada)" (SILVA, 2008, p. 332).

Pelo que é delegado ao Município a aprovação do projeto de loteamento, segundo critérios previamente definidos no Plano Diretor. E, como assinala Hely Lopes Meireles (2003, p. 540),

a aprovação de loteamento é ato da alçada privativa da Prefeitura, atendidas as prescrições da União, os preceitos sanitários do Estado e as imposições urbanísticas do Município, ouvidas previamente, quando for o caso, as autoridades militares e as florestais com jurisdição na área e o INCRA, se a gleba estiver na zona rural. Após a aprovação pela Prefeitura o loteamento deverá ser registrado no Registro Imobiliário competente, sendo passível de impugnação por terceiros (Lei 6.766, de 1979, arts. 19 e ss.) e de levantamento de dúvida pelo oficial do Registro (Lei 6.015, de 1973, arts. 198-204). O registro do loteamento produz, dentre outros, os seguintes efeitos imediatos: legitima a divisão e as vendas de lotes; torna imodificáveis unilateralmente o plano de loteamento e o arruamento; transfere para o domínio público do Município as vias de comunicação e as áreas reservadas constantes do memorial e da planta, independentemente de qualquer outro ato alienativo (art. 22 da Lei 6.766, de 1979). As alterações e o cancelamento do loteamento registrado só poderão ser feitos na forma e condições estabelecidas na Lei 6.766, de 1979, arts. 23 e 28.

Dessa feita, o Poder Municipal deve indeferir o projeto de loteamento que buscar parcelar o solo urbano em terrenos que tenham sido 
aterrados com material nocivo à saúde pública, sem que sejam previamente saneados, em terrenos com declividade igual ou superior a $30 \%$, salvo se atendidas exigências específicas das autoridades competentes, em terrenos onde as condições geológicas não aconselham a edificação, em áreas de preservação ecológica ou naquelas onde a poluição impeça condições sanitárias suportáveis, até a sua correção, nos termos do art. 3ํㅜ da referida lei.

Da mesma forma, o parcelamento do solo para fins urbanos comporta ônus a serem suportados pelo empreendedor, como arcar com as obras de infraestrutura (rede de abastecimento de água, energia, pavimentação, etc.) nos termos da lei municipal, a sujeição a servidões de áreas non edificandi e a transferência ao Município de áreas destinadas a sistema viário, equipamento urbano e comunitário e espaços livres, dentre outros (PINTO, 2007, p. 111-112).

Mesmo porque a Carta Magna prevê que a propriedade deve cumprir sua função socioambiental, tanto que ao tratar da política urbana, em seu art. 182, estabelece que "a política de desenvolvimento urbano, executada pelo Poder Público municipal, conforme diretrizes gerais fixadas em lei, tem por objetivo ordenar o pleno desenvolvimento das funções sociais da cidade e garantir o bem-estar de seus habitantes".

E, ainda, em seu $\S 2^{\circ}$, a Carta Magna, regulamenta que "a propriedade urbana cumpre sua função social quando atende às exigências fundamentais de ordenação da cidade expressas no plano diretor".

Coube, pois, ao Estatuto da Cidade (Lei n. 10.257 de 10/07/2001) (BRASIL, 2001) regulamentar o art. 182 da Constituição de 1988, donde se infere, também, uma séria preocupação ambiental, tanto que em seu art. $1^{\stackrel{o}{ }}$, par. ún. elenca o equilíbrio ambiental entre seus objetivos.

No entanto, o Estatuto expôs diretrizes gerais que devem guiar a política urbana, com o propósito de ordenar o pleno desenvolvimento das funções sociais da cidade e da propriedade urbana, dentre elas:

a garantia do direito a cidades sustentáveis (inc. I); corrigir os efeitos negativos das distorções do crescimento urbano sobre o meio 
ambiente (inc. IV); a ordenação e controle do uso do solo, de forma a evitar a poluição e a degradação ambiental (inc. VI); e a proteção, preservação e recuperação do meio ambiente natural e construído (inc. XII) (BELTRÃO, 2009).

Não obstante ao arrepio da lei urbanística e ambiental, verificamos inúmeros casos de parcelamento irregular do solo, com anuência ou não do poder público, responsáveis por vários problemas vivenciados pelos moradores das cidades brasileiras, com consequentes reflexos no meio ambiente e no desenvolvimento do País.

Nesse viés, como destaca a promotora de Justiça Rochelle Jelinek (2010, p. 2), em seu artigo "Licenciamento ambiental e urbanístico para o parcelamento do solo urbano",

com a diretriz imposta na Carta Magna, o Estado ou o particular que pretenda empreender deve evitar impactos que prejudiquem o ecossistema, a biodiversidade e o ordenamento das cidades e, por conseqüência, a qualidade de vida da população, porque o desenvolvimento econômico, a livre iniciativa e a livre exploração econômica subentendem o uso sustentável dos recursos naturais e o respeito aos limites do meio.

Dessa maneira, os loteamentos irregulares, em sentido amplo, ocasionam um vasto passivo a ser enfrentado, em decorrência dos impactos sociais, ambientais e econômicos ocasionados pelo desrespeito às prescrições das legislações ambientais e urbanísticas, bem como da violação ao princípio da dignidade da pessoa e do desenvolvimento sustentável, uma vez que a ocupação desordenada das cidades - fato que associado ao adensamento demográfico, à desigualdade social e fundiária, à exploração econômica exacerbada e à degradação ambiental - é uma realidade que torna inegável a insuficiência dos instrumentos de disciplina e fiscalização do uso do solo urbano (JELINEK, 2010, p. 1).

Nessa toada, verifica-se a formação de bairros sujeitos a erosão e alagamentos, assoreamento de rios, lagos e mares, comprometimento 
dos mananciais de abastecimento de água e do lençol freático, riscos de acidentes e incêndios decorrentes de ligações clandestinas de energia elétrica e aumento dos custos de urbanização (PINTO, 2007).

Nesse viés, então, o que dizermos das construções às margens dos rios ou nascentes aterradas, insistindo e agonizando ao brotar em casas? O Correio Braziliense veiculou, em 20 de junho de 2010, notícia sobre casas erguidas em lotes irregulares, a saber:

a lentidão das equipes de fiscalização e a rapidez dos grileiros constituem a fórmula ideal para o surgimento de um parcelamento irregular. No Lago Norte, essa velha receita está sendo usada mais uma vez. A venda de terrenos em área pública fez com que dezenas de casas surgissem ilegalmente em meio ao cerrado. O mais novo condomínio da cidade cresce rapidamente em uma área valorizada do bairro, próxima ao Centro de Atividades e com vista para o Parque Nacional de Brasília. Um lote de mil metros quadrados é vendido por apenas $\mathrm{R} \$$ 50 mil e a orientação dos responsáveis pela invasão é para que as edificações sejam concluídas ainda neste mês. A área é de propriedade da Companhia Imobiliária de Brasília (Terracap). A ideia dos compradores de lotes e dos grileiros é consolidar o condomínio o mais rápido possível para, assim, tentar evitar as derrubadas. Mas os moradores da região estão tranqüilos: eles dizem ter o respaldo de um funcionário da Agência de Fiscalização (Agefis) do Governo do Distrito Federal. "O Marcelo, que é da Agefis, tem uma casa aqui e prometeu que vai segurar a fiscalização por pelo menos mais 20 dias. Mas temos que correr com as obras até lá, para tudo estar bem consolidado. Aí, ninguém tem coragem de derrubar e a Justiça dá liminar a nosso favor", afirmou Antônio, que se identificou como morador da região e um dos negociadores de terrenos no novo condomínio irregular. [...] Garantiu que há 70 terrenos no condomínio e que a maioria já foi vendida. Segundo ele, "gente poderosa" forma a clientela. "Tem peritos da polícia, gente dos bombeiros e até advogados. Muita gente forte, que vai conseguir fazer com que o negócio saia do papel", afirmou. [...] A especulação imobiliária em torno da nova área grilada no Lago Norte cresce na mesma velocidade em que as edificações são erguidas. Os primeiros compradores pagaram cerca de $\mathrm{R} \$ 15$ mil pelos lotes irregulares e, hoje, esse valor já chega a $\mathrm{R} \$ 50$ mil, caso das áreas localizadas na beira da estrada de 
terra que leva ao parcelamento irregular. Os negociadores oferecem ainda lotes de $\mathrm{R} \$ 35$ mil na parte interna. Piquetes amarelos numerados demarcam os imóveis mas, segundo o negociador, é possível ampliar as ocupações para além do limite atualmente demarcado no condomínio. [...] Moradores da região e produtores rurais estão preocupados com o crescimento desordenado e com a grilagem de terras. O presidente do Conselho de Desenvolvimento Rural Sustentável do Lago Norte, Rubens Bartholo, afirma estar preocupado com o processo de "favelização" da área por conta do parcelamento irregular do solo. "Aquela região está virando uma favela e isso pode afetar seriamente o meio ambiente. O surgimento dos condomínios causa a impermeabilização do solo, o que gera impactos negativos nas chácaras", critica Rubens. [...] A Agência de Fiscalização (Agefis), segundo a assessoria de imprensa, informou que, até agora, não recebeu qualquer denúncia sobre o surgimento desse novo condomínio. Garantiu ainda que, se for comprovado o envolvimento de qualquer um de seus funcionários com o esquema de grilagem, o servidor responderá a um processo administrativo que pode culminar em demissão (MADER, 2010).

Essa ocupação irregular do solo urbano está presente tanto nos loteamentos clandestinos quanto nos loteamentos irregulares, com as mesmas condições desastrosas ao meio ambiente e desrespeito ao princípio do desenvolvimento sustentável, inserto no Estatuto da Cidade.

Os loteamentos clandestinos, como ensina o prof. José Afonso da Silva (2008, p. 344), são aqueles em que

loteadores parcelam terrenos de que, não raro, não têm título de domínio, por isso não conseguem a aprovação de plano, quando se dignam apresentá-lo à Prefeitura, pois, o comum é que sequer se preocupem com essa providência, que é onerosa, inclusive porque demanda a transferência de áreas de logradouros públicos e outras ao domínio público.

Nessas condições, feito o loteamento, não raros são os casos em que "põem-se os lotes à venda, geralmente para pessoas de rendas modestas, que, de uma hora para outra, perdem seu terreno e a casa que 
nele ergueram, também clandestinamente, porque não tinham documentos que lhes permitissem obter a competente licença para edificar no lote" (SILVA, 2008, p. 344).

No entanto, os loteamentos irregulares são aqueles aprovados pela Prefeitura, mas que não foram inscritos no Registro de Imóveis, ou o foram, mas são executados em desconformidade com a lei ou o plano e as plantas aprovadas.

Entretanto, sabe-se que o parcelamento irregular do solo urbano é uma prática corriqueira e crescente na sociedade e decorre, principalmente, das diversas restrições impostas pela Lei de Parcelamento do Solo Urbano, além dos enormes custos para se lotear e da imensa burocracia para a execução do projeto de loteamento, ineficiência ou até a complacência do poder público, bem como o fim do lucro desenfreado.

Verificam-se casos em que, obedecidas as restrições legais, levase algo em torno de cinco anos para a aprovação de um projeto para lotear uma área determinada, perante os órgãos do poder público, o que enseja que vários empreendedores caminhem por "via paralela" à legalidade, como, por exemplo, promoverem o parcelamento do solo em áreas de preservação permanente ou mesmo a venda de imóveis sem a prévia conclusão do processo de aprovação do loteamento, dentre outros inúmeros casos vivenciados no dia a dia das cidades.

Nos últimos anos, porém, proliferou-se absurdamente a irregularidade fundiária no Brasil, em razão desses fatos associados à condição do País estar "em fase de desenvolvimento" e inexistirem políticas públicas adequadas para a espécie, o que enseja dificuldade ainda maior da maioria das pessoas adquirem imóveis e serem levados às áreas irregulares.

Em outras palavras, essa realidade, associada ao fato de uma boa parte da população viver abaixo da linha de pobreza, sem condições de adquirir a própria moradia, no mercado imobiliário formal, em razão dos seus altos custos e a ausência de políticas governamentais adequadas, viabiliza constante aumento dos loteamentos clandestinos ou mesmo irregulares no País.

Como bem destaca José Afonso da Silva (2008, p. 345), cumpre 
notar que a Lei 6.766/1979 aparelhou um conjunto de normas, bastante rigorosas, destinadas a reprimir loteamentos ilegais e a punir seus promotores (arts. 37-52), inclusive dando poderes ao Município e ao Distrito Federal para empreender a regularização de tais loteamentos às expensas do loteador (art. 40). São providências de alto relevo, capazes de coibir parcelamentos ilegais do solo, se os Municípios se utilizarem adequadamente dessas disposições da lei. O Ministério Público, hoje, também dispõe de meios para providenciar a incriminação desses loteadores, já tendo conseguido alguns resultados, como a condenação deles a prisão. Mas, ainda assim, tais resultados não têm sidos suficientes para desestimular a prática desses crimes. Se não se havia de exculpar as Municipalidades pela existência desses loteamentos, agora à vista dos referidos textos legais, menos ainda. Ora, o loteamento pode ser clandestino, mas nunca será oculto. Realiza-se à vista de todos. Um pouco de organização e fiscalização evitariam que proliferassem e prosperassem tantos loteamentos ilegais.

Entretanto, os meios para coibir o parcelamento irregular do solo urbano são pouco utilizados pelo Poder Público ou mesmo ineficazes. Porém, as consequências por tal prática, determinam um obstáculo intransponível ao desenvolvimento nacional, como leciona Juarez Carlos de Freitas (1998, p. 16), a

desordenada ocupação do solo com a implantação dos loteamentos clandestinos, em virtude da inobservância das normas urbanísticas, conduz, assim, à proliferação de habitações edificadas sem critérios técnicos (insegurança) e em condições subumanas (insalubridade); ao surgimento de focos de degradação do meio ambiente e da saúde; ao adensamento populacional desprovido de equipamentos urbanos e comunitários definidos na Lei 6.766/79 (art. $4^{\circ}$, $§ 2^{\circ}$ e art. 5oㅜ par. ún.) e incompatível com o meio físico (má localização), gerando o crescimento caótico da cidade; à marginalização dos seus habitantes com o incremento das desigualdades sociais e reflexos na segurança da população local e circunvizinha (violência, comércio de drogas, promiscuidade).

Além disso, a ocupação irregular do solo urbano, como defende Patrícia Andre Camargo Ferraz (2010, p. 4-5), 
impõe ao cidadão a subutilização do imóvel que possui, já que restringe seu uso à moradia e eventualmente a um pequeno comércio. Tal se deve ao fato de a pessoa, que detém mera posse de imóvel, não dispor de direitos fortalecidos e oponíveis erga omnes relacionados ao bem de raiz. Assim, de tudo o que um imóvel poderia proporcionar a um indivíduo, àquele que mora em área irregular somente resta o mínimo: a posse precária, o mero abrigo das interpéries. A população de baixa e média renda normalmente tem seu patrimônio concentrado na casa edificada em terreno irregular. Por isso, os integrantes desses extratos sociais apenas dispõem da habitação em um imóvel, sem o respectivo título de propriedade, o que os impede de usá-lo como garantia real para a tomada de empréstimos em instituições de crédito públicas e privadas, com juros mais baixos. Os mútuos que constituem ou são realizados com garantias pessoais e, portanto, seus encargos financeiros são muito maiores do que aqueles que lhes seriam exigidos em contratos com garantia real, ou são efetivados em um mercado informal, onde as taxas de juros são também muito elevadas e as formas de execução contratual fogem às regras legalmente estabelecidas e aceitáveis. Não é só. Essa irregularidade enclausura os cidadãos em uma cela de insegurança jurídica quanto à ocupação e às transações que têm por objeto esses bens imóveis. Como essas pessoas não são, de acordo com o sistema jurídico brasileiro, proprietários dos imóveis que ocupam, e pelos quais muitas vezes já pagaram, não têm qualquer estímulo para investir em melhorias de suas casas e bairros.

Do contrário, movimenta-se a economia do País, "em razão de investimentos na melhoria de imóveis e porque viabiliza acesso a financiamentos menos custosos para investimentos em pequenos negócios e até mesmo para aquisição regular destes imóveis uma vez regularizados, etc." (BOFF, 2009, p. 3).

Isso porque, como demonstra Ferraz (2010, p. 5), esses investimentos, embora menores,

em larga escala (lembremo-nos que as cifras de irregularidade fundiária no Brasil podem atingir 2/3 das áreas urbanas e que nos demais países latinos este percentual pode chegar a 3/4), repercutiriam positivamente nas transações comerciais dos países, promovendo o desenvolvimento econômico de cada um deles. 
Outrossim, para ilustrar essa questão, tem-se a promulgação da Lei Federal n. 11.977 de 7 de julho de 2009 (BRASIL, 2009), a qual dispôs sobre o programa do Governo "Minha casa, minha vida", com objetivo geral de conceder meios para produção, aquisição e reforma de habitações e, por consequente, promover a regularização de inúmeras moradias no Brasil, a fim de atender toda população reprimida ao acesso à moradia adequada.

A Lei prevê diversos incentivos governamentais para a construção/aquisição/reforma da casa própria, como, por exemplo, subsídios variáveis conforme renda familiar, o que de, certa forma, facilitaria muito ou mesmo permitiria que pessoas que jamais sonhavam com a sua própria casa terem acesso a tal.

Contudo, o presente programa do Governo não atingiu boa parte dos seus objetivos pré-fixados até então, de atender a essa parcela da população, visto que ao buscar um financiamento com as pertinentes concessões - como taxa de juros, subsídio e prazo - esbarra em diversos problemas, os quais bloqueiam o enquadramento dessas pessoas nos requisitos legais necessários para tanto.

Um desses problemas é o fato de um grande número de imóveis terem sido adquiridos de maneira irregular, o que não permite, antes de sua prévia regularização, enquadrá-los nos benefícios governamentais. Por exemplo, um terreno adquirido em loteamento clandestino não terá como ter uma casa construída sobre si, financiada com os pertinentes subsídios governamentais, antes da sua prévia regularização.

\section{Conclusão}

Por todo o exposto, é de notar que do "caos que nasce a nova ordem. Devemos fazer de tudo para que o atual caos não seja destrutivo, mas criativo. Então sobrevivemos com o mesmo destino da Terra, a única casa comum que temos para morar" (FERRAZ, 2010, p. 3).

Vive-se, atualmente, uma época de mudanças. O Estado vem sendo reformulado em razão não de ideários reformatados e adaptados 
ao cotidiano modo de vida da sociedade, mas sim como decorrência inquestionável do nascimento de novos direitos aptos a conduzir ao desenvolvimento socioeconômico. Não se pode olvidar, ademais, que os direitos humanos também apresentam faceta adaptada ao meio ambiente. Trata-se do ecodesenvolvimento que não pode ser desconsiderado como forma de empreender não apenas o crescimento, mas também a própria autossustentável evolução da sociedade.

Em que pese falar-se em proteção ambiental, inserta no desenvolvimento em especial no que se refere ao parcelamento irregular do solo urbano, infelizmente também se verificam inúmeros casos de degradação ambiental pelos mais diversos motivos.

Como exposto no decorrer do texto, infrações recaem na violação de direitos humanos fundamentais, tais como, o direito à vida, à moradia, meio ambiente ecologicamente equilibrado e ao desenvolvimento (o qual, na verdade, abarca os demais).

Para a reversão desse quadro, faz-se necessária a promoção de políticas públicas adequadas à regularização desses empreendimentos imobiliários que compõem o mercado imobiliário informal, sejam loteamentos clandestinos ou mesmo irregulares, com a máxima urgência.

Para coibir a proliferação dos empreendimentos dessa ordem, também, devem ser tomadas medidas, em caráter preventivo ou repressivo. Até então, o controle tem-se limitado a adoção de medidas administrativas isoladas, como multas e embargos de obras, as quais sequer, muitas vezes, são obedecidas. O poder público, em alguns casos, abstém-se de determinar a demolição das edificações. Entretanto, a eficácia dessas medidas é limitada, diante da quantidade de infrações a serem combatidas e da omissão da maior parte das autoridades municipais (PINTO, 2007).

Uma primeira solução ao problema do passivo socioambiental e econômico ocasionado pela ocupação antrópica irregular do solo é uma atuação intensa no planejamento urbano pelo Município, desde a aprovação do projeto de loteamento, licenças e demais autorizações, durante a execução das obras aprovadas e, por fim, após a sua conclusão. 
Outrossim, o Poder Municipal precisa realizar fiscalização efetiva no parcelamento do solo urbano, deixando de lado políticas imediatistas e interesses políticos, pois assim, por exemplo, evitar-se-ia a abertura de ruas e lotes de terrenos em áreas de preservação permanente, como se vê diariamente nas cidades.

Ainda, necessária harmonização na atuação dos órgãos públicos e setoriais, através de um olhar do caso na sua totalidade e por meio de uma interpretação sistemática do ordenamento jurídico, seja ao momento de edição de uma lei ou decreto de aprovação pelo Município, ou mesmo quando do exercício da fiscalização da ocupação do solo por um ou outro órgão ambiental.

No mesmo sentido, clama-se por uma harmonia nas medidas de regularização do parcelamento irregular do solo. Por vezes, o Município estabelece diretrizes a serem seguidas na retificação necessária do projeto pelo loteador; contudo, o órgão ambiental competente pelo licenciamento ambiental não prevê tal possibilidade, impondo ao interessado sujeitarse aos mesmos ônus de um novo parcelamento do solo (como exemplo, requerer nova licença prévia).

O Poder Judiciário e, notadamente, o Ministério Público devem atuar na fiscalização das atividades do Poder Público e dos loteadores no parcelamento do solo urbano, a fim de se promover a devida responsabilização dos responsáveis pelos danos causados ao meio ambiente e a economia.

Essas questões são determinantes para o avanço na solução dos problemas socioambientais, urbanísticos e econômicos decorrentes do parcelamento irregular do solo urbano, a fim de que se possa promover a Política Urbana com vistas ao desenvolvimento sustentável, pois quanto "maior o número de sujeitos participantes do mercado imobiliário formal, maior o desenvolvimento econômico de cada localidade e maior a arrecadação de tributos, que poderão ser revertidos em investimentos em projetos que, direta ou indiretamente, combatam a pobreza" (FERRAZ, 2010, p. 9).

Utilizando-se das palavras de Sen (2008, p. 29), conclui-se que o "desenvolvimento tem que estar relacionado sobretudo com a melhoria da vida que levamos e das liberdades que desfrutamos". 


\section{Referências}

BELTRÃO, A. F. G. Direito ambiental. 2. ed. São Paulo: Método, 2009.

BOFF, L. Os limites do capital são os limites da Terra. São Paulo: Carta Maior-Econômica, 2009.

BRASIL. Presidência da República. Lei n. 6.766, de 19 de dezembro de 1979. Dispõe sobre o parcelamento do solo urbano e dá outras providências. Diário Oficial [da] República Federativa do Brasil, Poder Legislativo, Brasília, DF, 19 dez. 1979. Disponível em: <http://www.planalto.gov.br/ccivil_03/Leis/L6766. htm>. Acesso em: 23 jul. 2010.

BRASIL. Presidência da República. Lei n. 10.257, de 10 de julho de 2001. Regulamenta os arts. 182 e 183 da Constituição Federal, estabelece diretrizes gerais da política urbana e dá outras providências. Diário Oficial [da] República Federativa do Brasil, Poder Legislativo, Brasília, DF, 19 jul. 2001. Disponível em: 〈http://www.planalto.gov.br/ccivil_03/Leis/LEIS_2001/L10257.htm〉. Acesso em: 23 jul. 2010.

BRASIL. Presidência da República. Lei n. 11.977, de 7 de julho de 2009. Dispõe sobre o Programa Minha Casa, Minha Vida - PMCMV e a regularização fundiária de assentamentos localizados em áreas urbanas; altera o Decreto-Lei no 3.365 , de 21 de junho de 1941, as Leis nos 4.380 , de 21 de agosto de 1964, 6.015, de 31 de dezembro de 1973, 8.036, de 11 de maio de 1990, e 10.257, de 10 de julho de 2001, e a Medida Provisória no 2.197-43, de 24 de agosto de 2001; e dá outras providências. Diário Oficial [da] República Federativa do Brasil, Poder Legislativo, Brasília, DF, 7 jul. 2009. Disponível em: < http://www.planalto.gov. br/ccivil_03/_ato2007-2010/2009/lei/111977.htm>. Acesso em: 23 jul. 2010.

COLlaÇO, M. H. do V. R. Do direito ao desenvolvimento. Disponível em: <http://jus2.uol.com.br/doutrina/texto.asp?id=6038>. Acesso em: 15 set. 2010.

CONFERÊNCIA DAS NAÇÕES UNIDAS SOBRE MEIO AMBIENTE E DESENVOLVIMENTO. Agenda 21: Conferência das Nações Unidas sobre Meio Ambiente e Desenvolvimento. São Paulo: Secretaria de Estado do Meio Ambiente, 1997. 
FERRAZ, P. A. de C. Regularização fundiária e desenvolvimento econômico sustentado: algumas experiências do Brasil. Disponível em: <http://cinder. artisoftware.com/wp-content/uploads/file/DocumentosFortaleza/Ferraz.pdf 〉. Acesso em: 30 ago. 2010.

FREITAS, J. C. de. Loteamentos clandestinos e suas modalidades fraudulentas. Revista dos Tribunais, São Paulo, v. 750, p. 16-23, 1998.

FREITAS, M. A. P. de. O desenvolvimento sustentável dentro de uma perspectiva de direitos humanos e direito ambiental internacional. In: PIOVESAN, F. Direitos humanos. Curitiba: Juruá, 2006. p. 245-250.

FREITAS, V. P. de. A Constituição Federal e a efetividade das normas ambientais. 3. ed. São Paulo: Revista dos Tribunais, 2005.

GABARDO, E. Interesse público e subsidiariedade: o estado e a sociedade civil para além do bem e do mal. Belo Horizonte: Fórum, 2009.

JELINEK, R. Licenciamento ambiental e urbanístico para o parcelamento do solo urbano. Disponível em: <http://www.mp.go.gov.br/portalweb/hp/9/ docs/doutrinaparcel_19.pdf $>$. Acesso em: 4 set. 2010.

LEFF, E. Saber ambiental: sustentabilidade, racionalidade, complexidade, poder. Petrópolis: Vozes, 2001.

MADER, H. Casas são erguidas em lotes irregulares no Lago Norte. Disponível em: <http://www.correiobraziliense.com.br/app/noticia182/2010/06/20/ cidades, $\mathrm{i}=198519 /$ casas+sao+erguidas+em+lotes+irregulares+no+lago+norte. shtml>. Acesso em: $1^{\circ}$ set. 2010.

MARÉS FILHO, C. F. Direitos invisíveis. In: OLIVEIRA, F. de.; PAOLI, M. C. (Org.). Os sentidos da democracia: políticas do dissenso e hegemonia global. Petrópolis: Vozes; Brasília: Nedic, 1999. p. 55-81.

MARÉS FILHO, C. F. Bens culturais e sua proteção jurídica. 3. ed. Curitiba: Juruá, 2006. 
MEIRELLES, H. L. Direito municipal brasileiro. 13. ed. Atualizada por Célia Marisa Prendes e Márcio Schneider Reis. São Paulo: Malheiros, 2003.

MOREIRA, V. A ordem jurídica do capitalismo. 3. ed. Coimbra: Centelha, 1978. NUSDEO, F. Curso de economia: introdução do direito econômico. In: GABARDO, E. Interesse público e subsidiariedade: o estado e a sociedade civil para além do bem e do mal. Belo Horizonte: Fórum, 2009. p. 341-395.

PINTO, V. C. Ocupação irregular do solo e infra-estrutura urbana: o caso da energia elétrica. In: FREITAS, J. C. (Coord.). Temas de direito urbanístico 5. São Paulo: IMESP, 2007. p. 111-112.

PIOVESAN, F. Direitos humanos e o direito constitucional internacional. 11. ed. São Paulo: Saraiva, 2010.

RISTER, C. A. Direito ao desenvolvimento: antecedentes, significados e conseqüências. Rio de Janeiro: Renovar, 2007.

SACHS, I. Rumo à ecossocioeconomia: teoria e prática do desenvolvimento. São Paulo: Cortez, 2007.

SEN, A. Desenvolvimento como liberdade. Tradução de Laura Teixeira Motta. São Paulo: Companhia das Letras, 2008.

SILVA, J. A. da. Direito urbanístico brasileiro. 5. ed. São Paulo: Malheiros, 2008. SIRVINSKAS, L. P. Manual de direito ambiental. 7. ed. São Paulo: Saraiva, 2009. TRINDADE, A. A. C. Direitos humanos e meio ambiente: paralelo dos sistemas de proteção internacional. Porto Alegre: Sérgio Antonio Fabris, 1993.

VEIGA, J. E. da. Desenvolvimento sustentável: o desafio do século XXI. 3. ed. Rio de Janeiro: Garamond, 2008.

Recebido: 01/03/2011

Received: 03/01/2011 